\title{
The Study of Influence of Nutritional Factors Supply Indicators of Blood Laboratory Animals Using Nonparametric Statistics
}

\author{
Kvan O.V.", Lebedev S.V., Akimov S.S., Bykov A.V. \\ Orenburg State University, Orenburg, Russia \\ *Corresponding Author: kwan111@yandex.ru
}

Copyright (C) 2013 Horizon Research Publishing All rights reserved.

\begin{abstract}
The aim of the study was to analyze using non-parametric statistical method, a number of morphological and biochemical parameters of laboratory animals' blood on a diet deficient in minerals, with additional introduction of probiotics (sporobakterin, bifidobakterin) and iron preporations with different physical and chemical properties.

The studies were performed in the experimental-biological clinics (vivarium) Orenburg State University. The seventy female rats of Wistar strain at the age of 4-months, identical in weight, were in the period prior experience in a balanced diet (feed stuff) were selected. During the experiment, the animals were divided into seven groups (one control group and six experimental) based on probiotic added to the feed (sporobakterin, bifidobakterin) and iron preparations («Gemofer» (Poland), the iron oxide fine powder). All experimental animals for the experiment (28 days) were on a diet deficient minerals that achieved through the drinking water of the experimental animals with distilled water and prepared in a particular way feeding rice (polished rice cooking for 15 minutes, followed by removal of broth and washing with distilled water). In order to prevent vitamin deficiency states active in the diet was administered multivitamin complex containing vitamins $\mathrm{A}, \mathrm{D}, \mathrm{E}, \mathrm{B}_{1}, \mathrm{~B}_{2}$, $\mathrm{B}_{3}, \mathrm{~B}_{4}, \mathrm{~B}_{5}, \mathrm{~B}_{6}, \mathrm{~B}_{\mathrm{c}}, \mathrm{B}_{12}$. Thus, the using of finely divided iron oxide powder as a mono-therapy, and also the using together with sporobacterin result to an increase of hemoglobin, the color index and serum iron in the blood of laboratory animals. In our opinion, this expectation may be attributed to the fact that the normal flora of the gastrointestinal tract does not feel the need for this preparation and does not compete with macro organism for iron.
\end{abstract}

Keywords Hemoglobin, Mineral Deficiency Diet, Iron, Sporobakterin, Bifidumbakterin

\section{Introduction}

The problem of iron deficiency has a great practical interest. According to WHO data about one third of the world population has latent iron deficiency and iron deficiency anemia.

Keen interest of researchers to this problem is connected not only with the prevalence of iron in nature, but with the participation of its complex metabolic processes in the human body [9]. The fact is not of little important but the concentration of iron is regulated with absorption exclusively, and not with the release. An active part in the regulation of sorption and excretion of anions, cations, water takes the intestinal microflora. However, the ambiguous influence of probiotics on the mineral metabolism of humans and animals [2]. For some bacterial consumption of iron in a host organism because it is difficult insolubility at neutral and mildly alkaline $\mathrm{pH}$. Several authors demonstrated that probiotic strains are able to enhance endogenous loss of mineral elements by incorporating and excretion .

The appearance of technical capacity of metal nanopowders allowed expanding research on the joint use of nanoparticles and probiotics. However, information on its joint application and impact on the micro element composition of the body is insufficient.

The aim of the study was to analyze using non-parametric statistical method, a number of morphological and biochemical parameters of laboratory animals' blood on a diet deficient in minerals, with additional introduction of probiotics (sporobakterin, bifidobakterin) and iron preporations with different physical and chemical properties.

\section{Materials and Methods}

The studies were performed in the experimental-biological clinics (vivarium) Orenburg State University. The seventy female rats of Wistar strain at the age of 4-months, identical in weight, were in the period prior experiences in a balanced diet (feed stuff) were selected. [6]

During the experiment, the animals were divided into seven groups (one control group and six experimental) based 
on probiotic added to the feed (sporobakterin, bifidobakterin) and iron preparations («Gemofer» (Poland), the iron oxide fine powder).

All experimental animals for the experiment (28 days) were on a diet deficient minerals that achieved through the drinking water of the experimental animals with distilled water and prepared in a particular way feeding rice (polished rice cooking for 15 minutes, followed by removal of broth and washing with distilled water). In order to prevent vitamin deficiency states active in the diet was administered multivitamin complex containing vitamins $\mathrm{A}, \mathrm{D}, \mathrm{E}, \mathrm{B}_{1}, \mathrm{~B}_{2}$, $\mathrm{B}_{3}, \mathrm{~B}_{4}, \mathrm{~B}_{5}, \mathrm{~B}_{6}, \mathrm{~B}_{\mathrm{c}}, \mathrm{B}_{12}[4]$.

Sporobacterin (the culture of Bacillus subtilis № 534) is a self-eliminated monoprobiotik. The suspension of bacteria grown on lactose free medium contains $1 \mathrm{ml}$ of $10^{9} \mathrm{CFU}$. The optimum dosage for animals $10.8 \mathrm{ml} / \mathrm{kg}$ feed (P.I. by Zhdanov, 1991).

Probiotic bifidumbakterin (strain Bifidobacterium longum), $1 \mathrm{ml}$. preparation contains about 107 microbial bodies, the optimal dosage $-10 \mathrm{ml} / \mathrm{kg}$ of feed (by M.B. Zinberg, 2001).

Gemofer (Poland) - antianemic preparation containing iron in the form of a simple salt chloride, iron (II) was administered at the rate of $1.5 \mathrm{mg} / \mathrm{kg}$ body weight.

Super fine powder of iron oxide core with $\mathrm{Fe}^{+3}$, obtained by mechanic-chemical method was introduced mainly spherical particle size of $120 \pm 15 \mathrm{~nm}$. Animals received a powder rate of $7 \mathrm{mg} / \mathrm{kg}$ feed

Experimental animals of group I received the basic diet supplemented with mineral deficiency of fine iron powder ; II group - the main mineral deficiency diet with the addition of the drug «Gemofer» (Poland ); III - mineral deficiency basic diet supplemented with probiotic sporobakterin and superfine iron powder ; IV - the main diet mineral deficiency with the addition of probiotic sporobakterina and preparation «Gemofer»; V - mineral deficiency basic diet supplemented with probiotic bifidumbacterin ; VI - mineral deficiency basic diet supplemented with probiotic sporobakterin .

Statistical analysis was performed using the PC («Microsoft Office Excel», STATISTICA 6), which included the definition of normality distribution using the method of Kruskal -Wallis and Mann- Whitney criterion.

\section{Results and Discussion}

Analysis of the observations was carried out by checking the sample for normal distribution for the recommended algorithm of Aivazyan S.A., Mkhitaryan V.S. (1998).

Graphical interpretation allowed visually assess the discrepancy normal distribution bell chart, draw the red line. Along with this, the analysis of the data was used the nonparametric Mann-Whitney criterion $[5,7,8]$.

The research showed that the addition of iron preparations had the most significant impact on the level of hemoglobin, which was significantly $(p \leq 0,01)$ higher in the experimental group I to $31.0 \%$ in II - by $17.0 \%$ in IV - on $25,3 \%, \mathrm{~V}$ - by
$30.0 \%$, and VI - by $23.9 \%$, the exclusion is a group with the addition of probiotic preparation sporobakterina and iron preparation «Gemofer».

The most important fact of iron metabolism in the body is the level of serum iron. According to our data, in the experimental groups $\mathrm{V}$ and VI was observed a significant reduction of iron in the blood a 2.2 -fold $(p \leq 0,001)$ towards the control, in the group IV - nonsignificant decrease by 2.7 fold. In I, II and III of the experimental groups showed a tendency toward increasing of level of iron, which in absolute terms amounted to $169.6,172.2$ and $171.9 \mathrm{mmol} / \mathrm{L}$, respectively.

Thus, I - IV experimental groups occurred nonsignificant increase in the number of red blood cells to $7.3 \%$.

In assessing of the color index level (which expresses the degree of saturation of the hemoglobin of red blood cells) in the body of the test specimens Significant changes in the direction of increasing iron $(\mathrm{p} \leq 0,05)$ were observed in the experimental groups I, IV and V by comparing with the group that was contained in the mineral deficiency diet. However, all groups showed increasing of this index.

A similar pattern was observed for total protein and albumin, an increasing in the content of the latter was in the experimental groups. Significant changes from a protein identified in the II and III experimental group ( $\mathrm{p} \leq 0,05)$, to albumin - in I, III and VI $(\mathrm{p} \leq 0,05)$.

\section{Conclusion}

Thus, the using of finely divided iron oxide powder as a mono-therapy, and also the using together with sporobacterin result to an increase of hemoglobin, the color index and serum iron in the blood of laboratory animals. In our opinion, this expectation may be attributed to the fact that the normal flora of the gastrointestinal tract does not feel the need for this preparation and does not compete with macro organism for iron.

\section{REFERENCES}

[1] Ajvazjan, S.A. Applied of the statistican and bases ekonometriki / S.A. Ajvazjan, V.S. Mhitaryan// - M: UNITI.- 1998.-P.1022.

[2] Badretdinova, L.M. Makro and trace substances and an intestinal microflora of the person // L.M.Badretdinova. II consilium of the Russian society medical elementology.-2008.-P. 46.

[3] Iglin, S.P. Probability theory and the mathematical statistics on the basis of MATLAB / S.P. Iglin // Publ. house NTU "HPI", Kharkov, Ukraine.- 2006.-612 P.

[4] Kvan, O.V. The influence of probiotic preparations on the basis of cultures Bacillus subtilis and Bifidobacterium longum on efficiency a metabolism and the mineral status of an organism of hens-layers.: autoref. .... diss./ O.V.Kvan. - 
Orenburg, 2007. $-22 \mathrm{p}$.

[5] Orlov, A.I. About application of statistical methods in medicobiological researches / Magazine «Bulletin of Academy of medical sciences of the USSR». 1987.-№2. C.88-94.

[6] Poryadkov, L.F. Base of model for studying of problems artificial feeding deliveries in experiment / L.F. Poryadkov. M: Scientific research institute of first aid of Sklifosovsky, 2001.-P.103-131.
[7] Rebrov, V.G. The statistical analysis of the medical data. Usage package of applied programs STATISTICA / V.G. Rebrov //. - M.: Mediasphere, 2002.-312 p.

[8] Sidorenko, E. V. Method of mathematical processing in psychology / E.V. Sidorenko // SPb.: Open Company "Speech".- 2007. - 128 p.

[9] Skalny, A.V. Analytical methods in bioelementology / A.V. Skalny, E.V. Lakarova, V.V. Kuznetsov, M.G.Skalnaya. SPb.: Science, 2009.-264p. 